\section{Contrecoup Injury}

Beth Rush

Psychiatry and Psychology, Mayo Clinic, Jacksonville, FL, USA

\section{Definition}

Contrecoup injury is an injury to the brain tissue directly beneath the skull, opposite to the point of impact. It results from acceleration-deceleration events during which the force impacting the head causes the brain to slam into the skull on the opposite side of the blow. Motor vehicle accidents, falls, sports injuries, and physical assaults with blunt objects frequently result in contrecoup injuries. Skull characteristics make the most probable sites of injury in the frontal and temporal lobes, as tips of the skull can more easily be forced into the underlying brain tissue in the frontal and temporal lobes. Neuropsychological evaluation can help to identify cognitive impairments arising from both the primary and secondary sites of injury.

\section{Cross-References}

Acceleration Injury

- Biomechanics of Injury

- Cortical Contusion

- Traumatic Brain Injury

\section{References and Readings}

Graham, D. I., Saatman, K. E., Marklund, N., Copnte, V., Morales, D., Royo, N., \& McIntosh, T. K. (2006). The neuropathology of trauma. In R. W. Evans (Ed.), Neurology and trauma (2nd ed., pp. 45-94). New York: Oxford University Press. 